\title{
Reliability Fuzzy Comprehensive Evaluation based on construction monitoring long-span arch truss
}

\author{
Kongliang Chen ${ }^{1, *}$, Guoqing Yuan ${ }^{1}$, Liankun Wang ${ }^{1}$ \\ ${ }^{1}$ School of Civil Engineering, Wuyi University, Jiang men, 529000, Guangdong, China
}

\begin{abstract}
The steel roof of the West Stand structure in Jiangmen Sports Center is a super-span space steel tube truss arch structure. In this article, the simulation analysis, and construction monitoring process, and the arch foot deformation monitoring is researched systematically, and the fuzzy reliability analysis is established based on the construction monitoring process. The monitoring results show that the roof structure is in healthy state, and the arch foot deformation meets the design requirements, which means that detailed simulation calculation provides theoretical basis for construction monitoring, and the measured data agree well with the theoretical data. Reliability Fuzzy Comprehensive Evaluation of structural monitoring adopts a layered weighting method by dividing the entire structural monitoring into several types of key monitoring indicators, corresponding analysis is carried out according to the calculation formula of the weight of various indicators to solve the reliability problem of structural monitoring. It is shown through analysis that this method can provide an effective basis for on-site safety construction, and the above conclusions can provide references for related projects in the future.
\end{abstract}

\section{Introduction}

The large-span complex space truss structure is widely used in various major buildings because of its beautiful appearance and reliable structure. However, Large-span steel structure has a large span and complex forces ${ }^{[1-4]}$, and the potential for damage and destruction is particularly high during the construction phase. There are many hidden safety hazards in the construction of large-span steel structures. In the last two decades, some major safety accidents have occurred. A roof collapse accident occurred in the 2E terminal of Paris Charles de Gaulle International Airport in May 2004, causing many people were unfortunately killed, and a large factory building in Shanghai collapsed during construction in July 2009 with an area of about 20,000 square meters and the main steel structure of the platform collapsed, and a collapse accident occurred during the demolition of the Shenzhen Sports Center in July 2019. Therefore, monitoring the stress and deformation during the construction phase is of great importance for ensuring the structural safety ${ }^{[-8]}$. And there are less research on construction monitoring ${ }^{[9-}$ ${ }^{10]}$ of large arch trusses at present. There are relatively few research results on long-span arch truss construction monitoring and corresponding reliability analysis.

In response to the above problems, the large-span arch truss has a novel structure and complex forces. It is still insufficient in on-site monitoring, measurement and early warning, which greatly reduces the role of monitoring and measurement on site construction guidance. Supported by on-site monitoring data and based on structural reliability design principles, a probabilistic early warning system for construction monitoring has been established, which provide references for related projects in the future.

\section{Project Overview}

The steel structure of the West Stand roof consists of arch trusses, truss beams, and canopies that cantilevered to the sides, and the material of the steel structure is Q345B, as shown in Fig.1. The cross section of the arch truss is an inverted triangle, and the arch feet at both ends are supported on the ground, of which the theoretical span between the arch feet is about $260 \mathrm{~m}$ with $50 \mathrm{~m}$ height from arch to ground, including the size of the concrete support. The arch truss is composed of round steel pipes tilted out of the field, which is supported on the roof truss beam by setting arch support rods, and one end of the roof truss beam is hinged to the lower concrete outer edge column, and the other end is hinged to the lower chord steel pipe of the arch frame. The cross section of the main truss arch is round steel pipe, and those of the cantilevered beam above the main truss arch is $\mathrm{H}$-shaped steel beam, and the other rod sections are mainly round tubes. To ensure the overall rigidity of the roof, diagonal braces are set in the middle of the truss beams, and stable trusses are set at the mid-span and ends.

\footnotetext{
${ }^{*}$ Corresponding author: kongliangchen@126.com
} 


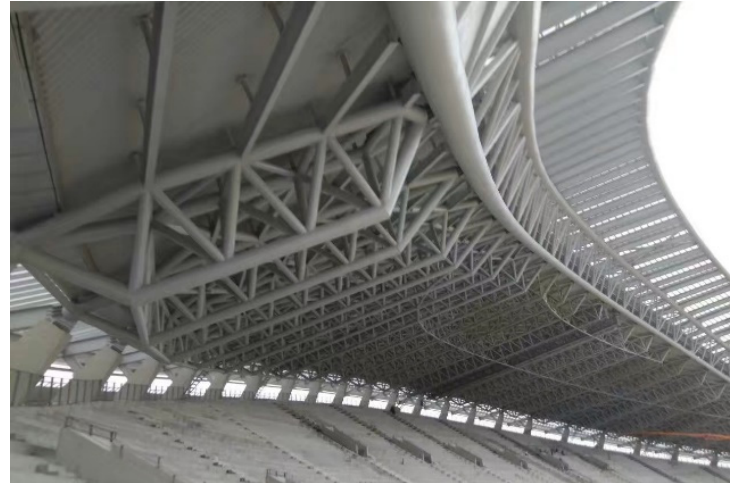

Figure 1. The steel roof structure of West Stand

\section{Analysis of construction technology}

\subsection{Construction process and simulation calculation}

The entire arch truss is divided into 11 segments, and the arch truss of each segment is fixed to the temporary support by hoisting from the bottom to the middle of the stands on both sides, and then the radial truss is installed, which is assembled from both sides to the middle high altitude, as shown in Figures 2.

The structure of the west stand needs to be unloaded as a whole, and the unloading tonnage is about 1900t. For the purpose of ensuring the safety of the structure and the overall appearance, it is necessary to control the key points to descend simultaneously. However, the roof unloading organization is so complicated that it must have corresponding guarantee measures for the entire unloading process implemented according to the established plan, which requires calculating the actual value before the unloading phase. Therefore, the overall unloading must theoretically be calculated accurately for safety. Construction simulation calculations are performed using Midas finite element program. According to the parameters of the design and construction drawings, the main truss and other members are simulated by beam element, and supports are simplified as hinges, which is shown in Figure 3, and there are 5580 elements with a total of 30 sections.

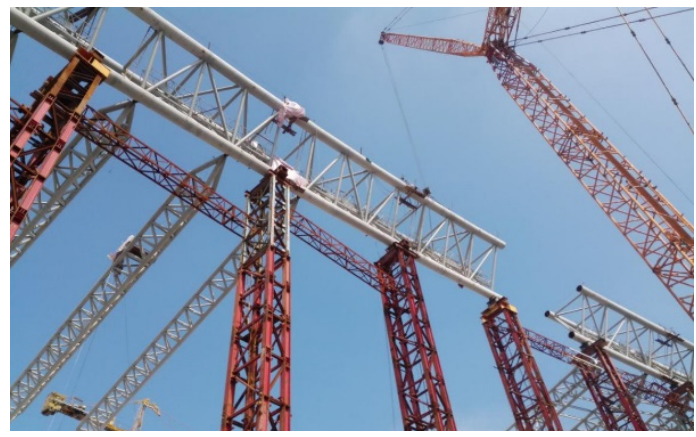

Figure 2. Main truss installation

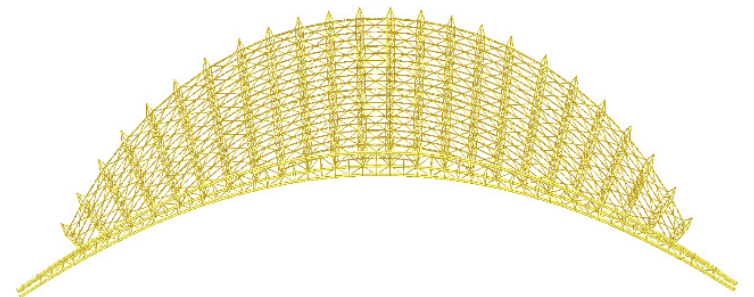

Figure 3. Calculation model

On the basis of the construction characteristics and construction monitoring requirements of the west stand roof structure, the finite element step-by-step formal installation calculation method is used. In theoretical analysis, the vertical displacement of unloading stage has a large change, while the horizontal displacement changes little. Therefore, Vertical displacement is the key stage of construction monitoring.

As shown in Figure 4, there are three stress monitoring sections for the main truss of the West Stand, which are section $\mathrm{A}$, section $\mathrm{B}$, and section $\mathrm{C}$, and each rod has 4 sensors and each section has 12 sensors, and section $\mathrm{A}$ is at the vault, section $\mathrm{B}$ and section $\mathrm{C}$ are at the arch feet. The displacement monitoring points of the main arch are at the arch vault and arch feet, and one measuring point is on the vault, and 4 measuring points on each of the two arch feet, and S1,S2,J1,J2 are in left arch foot, and $\mathrm{Q} 1, \mathrm{Q} 2, \mathrm{~T} 1, \mathrm{~T} 2$ are in right arch foot. The radial truss displacement monitoring points are located at the junction of the radial truss and the column, and there are a total of 8 radial truss measuring points. The $\mathrm{X}$-axis in the figure is basically coincident with the line connecting the centers of the two arch feet, and the Z-axis is vertical. There are 15 stages in the construction monitoring of the structure, and 18 stages in the deformation monitoring of the arch foot, and the 11th stage is the roof unloading stage, and the stress monitoring of the arch vault starts from the 7 th stage.

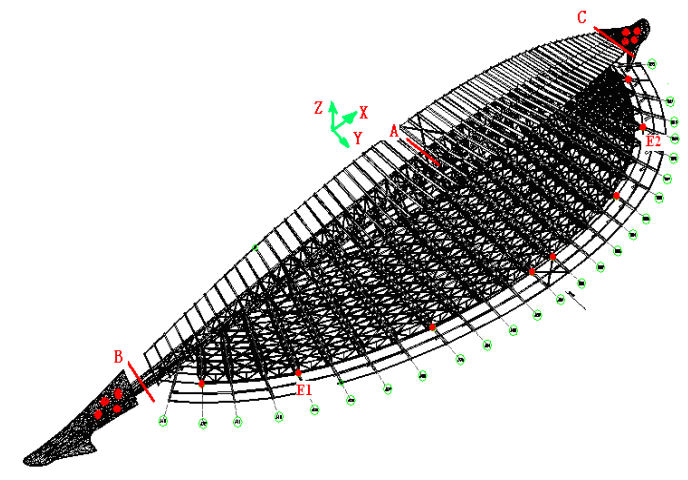

Figure 4. Schematic diagram of measuring points

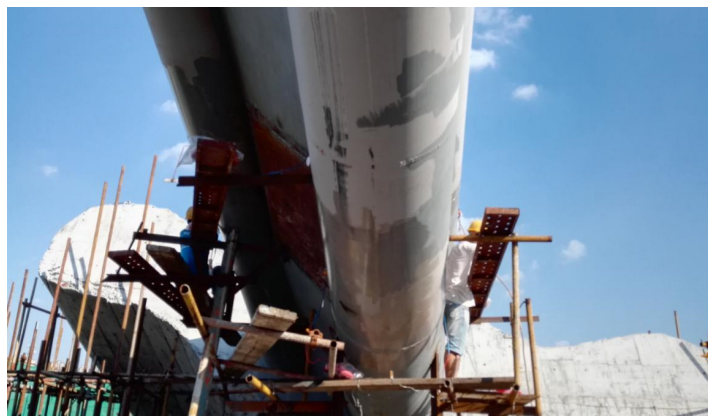

Figure 5. Installation of the arch foot strain gauge 


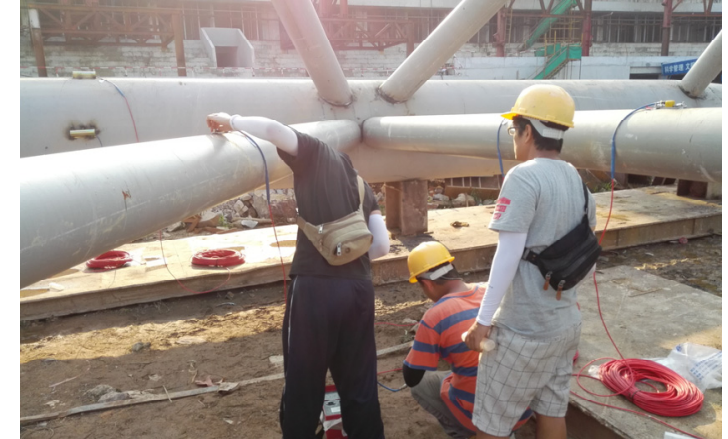

Figure 6. Installation of arch vault strain gauge

The monitoring system of this project is mainly composed of sensor subsystem, data collection subsystem and so on, which can realize continuous collection of monitoring data, and continuous real-time monitoring. The sensor subsystem arranges sensors in key parts of the structure according to construction monitoring scheme, which is used to obtain the response information under load, and the stress installation of the arch top and arch foot is shown in Figures 5-6.

\subsection{Stress and deformation monitoring results and analysis}

The process from the closing of the arch truss to the removal of the support of the tire frame completes the transition from the temporary support tower load to the steel structure. This is a process of gradually transferring the permanent structure and redistributing internal forces. Due to more measured points and data, this article only selects part of the stress measured points for analysis, and finds out the corresponding laws.

It can be seen from figures 7-8 that the stress curve of the arch foot measurement point is basically uniform before unloading, the curve variation is in the range of

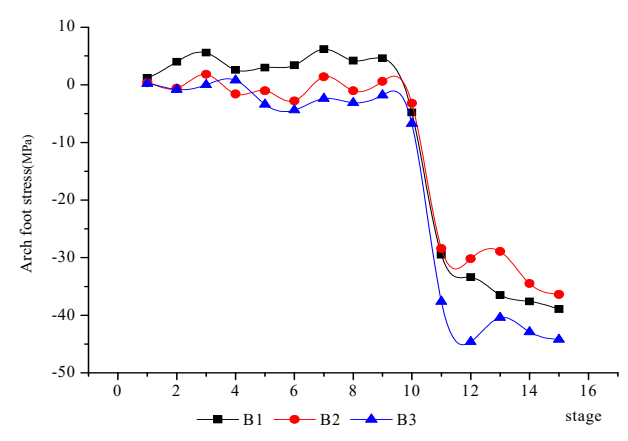

Figure 7. Stress change of left arch foot about $-10 \mathrm{MPa} \sim 10 \mathrm{MPa}$, and the internal force change law of the arch foot measurement point is roughly similar. During the unloading of tire frame, the stress data suddenly increased sharply about 20 to $40 \mathrm{MPa}$, but it is far less than the yield strength of the steel. After the unloading, the internal force of the rod is gradually transferred and the internal force is redistributed, but the overall change is not large. And the stress curve of the vault measurement point has obvious abrupt change during the unloading stage, and vault stress will gradually increase and finally stabilize, and this process is similar to the stress change of the arch foot.

As shown in Table 1, assuming tensile stress is positive, the stress data in the unloading stage have large variations, which is generally about 20 to $30 \mathrm{MPa}$. Moreover, the ratio of the measured stress data in most rods to the theoretical value is about 0.6 to 0.95 , which is in a reasonable range, but there are also some points of data that are not in this range because of temperature or environmental impact. The comparison of measured stress and theoretical stress fully demonstrate the correctness of theoretical analysis.

Due to more measured points and data, this article only selects part of the displacement measured points for analysis, and finds out the corresponding laws.

It can be seen from the figures 9-10 that when the roof structure is unloaded, the horizontal deformation of the arch foot has a sudden change about $3 \sim 6 \mathrm{~mm}$, but the deformation of the arch foot slightly decreases and gradually stabilizes in the subsequent stage.

From the results in Table 2, it can be seen that the distance between the two measuring points of the arch foot is pushed outward after the tire frame is removed, and the distance between the two points has increased by about 4 $\sim 9 \mathrm{~mm}$, but the actual monitoring result is smaller than the theoretical calculation, which shows that the arch foot stiffness is greater than the calculated value of the theoretical model.

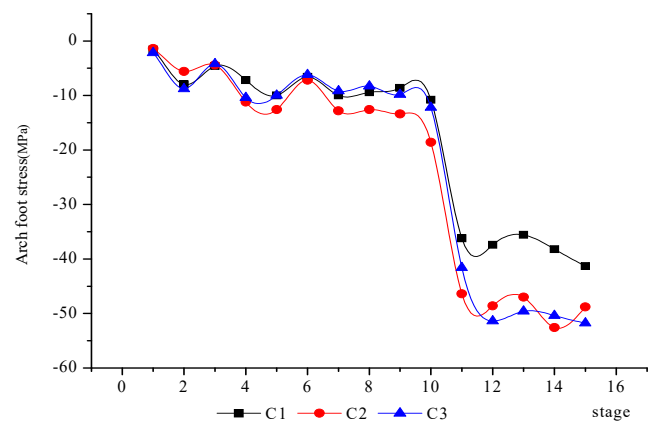

Figure 8. Stress change of the right arch foot 


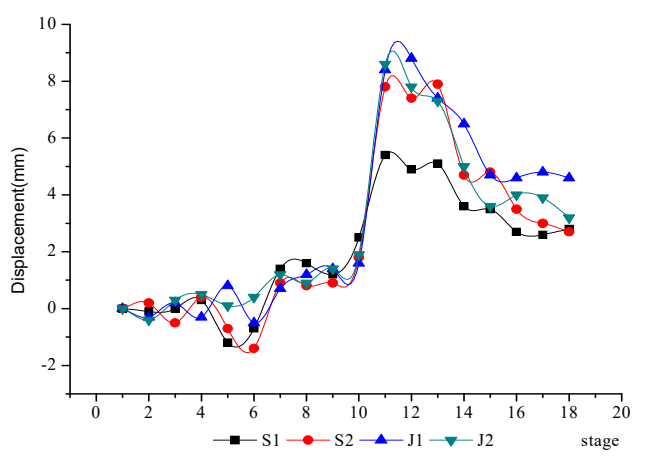

Figure 9. Deformation of the left arch foot

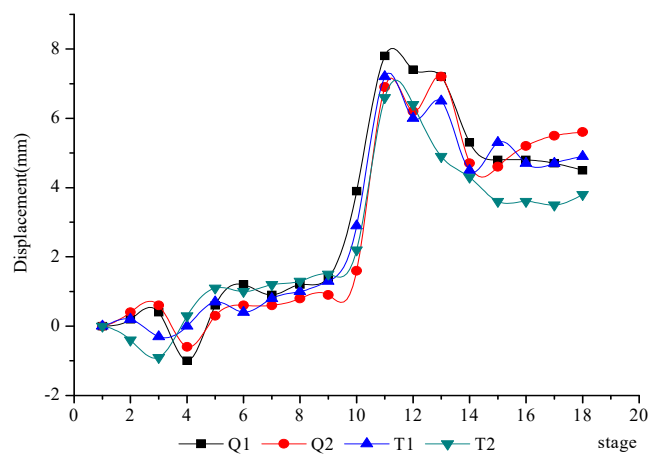

Figure 10. Deformation of the right arch foot

Table1. Comparison of stress values during unloading

(Unit:MPa)

\begin{tabular}{rcccccc}
\hline \multirow{2}{*}{$\begin{array}{c}\text { Serial } \\
\text { number }\end{array}$} & position & \multicolumn{2}{c}{ Construction stress } & Change in stress & Theoretical stress & \multicolumn{2}{c}{ Value comparison } \\
\cline { 2 - 7 } & & Stage 10(1) & Stage 11( (2) & (2)-(1) & Stage 11(3) & (2)/(3) \\
\hline \multirow{2}{*}{$\begin{array}{c}\text { Section } \\
\text { A }\end{array}$} & A1 & -10.4 & -22.9 & -12.5 & -30.4 & 0.41 \\
\cline { 2 - 7 } & A2 & -14.7 & -37.8 & -23.1 & -30.4 & 0.76 \\
\hline \multirow{2}{*}{ Section B } & -11.2 & -39.4 & -28.2 & -30.4 & 0.93 \\
\cline { 2 - 7 } & B2 & -4.8 & -29.5 & -24.7 & -40.6 & 0.61 \\
\hline \multirow{2}{*}{ Section C } & B3 & -3.2 & -28.4 & -25.2 & -40.6 & 0.62 \\
\cline { 2 - 7 } & C1 & -10.8 & -37.6 & -30.9 & -40.6 & 0.63 \\
\hline
\end{tabular}

Table2. Deformation comparison before and after unloading

(Unit: $\mathrm{m}$ )

\begin{tabular}{ccccccc}
\hline \multirow{2}{*}{ Left } & \multirow{2}{*}{ Right } & Straight line & Distance between two measuring points & Measured value & Allowable value \\
\cline { 3 - 6 } & & & Before & After & $\Delta \mathrm{L}$ & {$[\triangle \mathrm{L}]$} \\
\hline $\mathrm{S} 1$ & $\mathrm{Q} 1$ & $\mathrm{~S} 1 \mathrm{Q} 1$ & 266.575 & 266.579 & 0.004 & 0.018 \\
\hline $\mathrm{S} 2$ & $\mathrm{Q} 2$ & $\mathrm{~S} 2 \mathrm{Q} 2$ & 264.526 & 264.535 & 0.009 & 0.018 \\
\hline $\mathrm{J} 1$ & $\mathrm{~T} 1$ & $\mathrm{~J} 1 \mathrm{~T} 1$ & 271.727 & 271.735 & 0.008 & 0.018 \\
\hline J2 & T2 & J2T2 & 273.505 & 273.511 & 0.006 & 0.018 \\
\hline
\end{tabular}

\section{Theoretical analysis of structural reliability}

In the reliability fuzzy evaluation of structural monitoring, the whole can be divided into three types of indicators as shown in Figure 11. And fuzzy evaluation is the first category of indicators, and arch foot monitoring, main truss monitoring and radial truss monitoring are the second category of indicators, and the other are the third category of indicators. The first type of indicators can be obtained through expert survey methods to obtain the weights of corresponding factors, while the evaluation of other types of indicators can be obtained through the hierarchical weighting method based on the monitoring data information, and the key task is to determine the calculation method of the underlying monitoring indicators.

For the first type of indicators, the five technical conditions can refer to the specification ${ }^{[11]}$, and the fuzzy evaluation level can be determined according to the calculated score. For the second index, a dimensionless model can be used to process the value according to the percentage system. For the third indicator, the monitoring data is the evaluation indicator of the data sequence, and it needs to be processed appropriately dimensionless to make the detection results of each measurement point comparable. The classification of the monitoring data is shown in Table 3. 
Table3. Monitoring rating level

\begin{tabular}{cccccc}
\hline Rating & Level one & Level two & Level three & Level four & Level five \\
\hline Points & $80 \sim 100$ & $60 \sim 79$ & $40 \sim 59$ & $20 \sim 39$ & $0 \sim 19$ \\
\hline
\end{tabular}

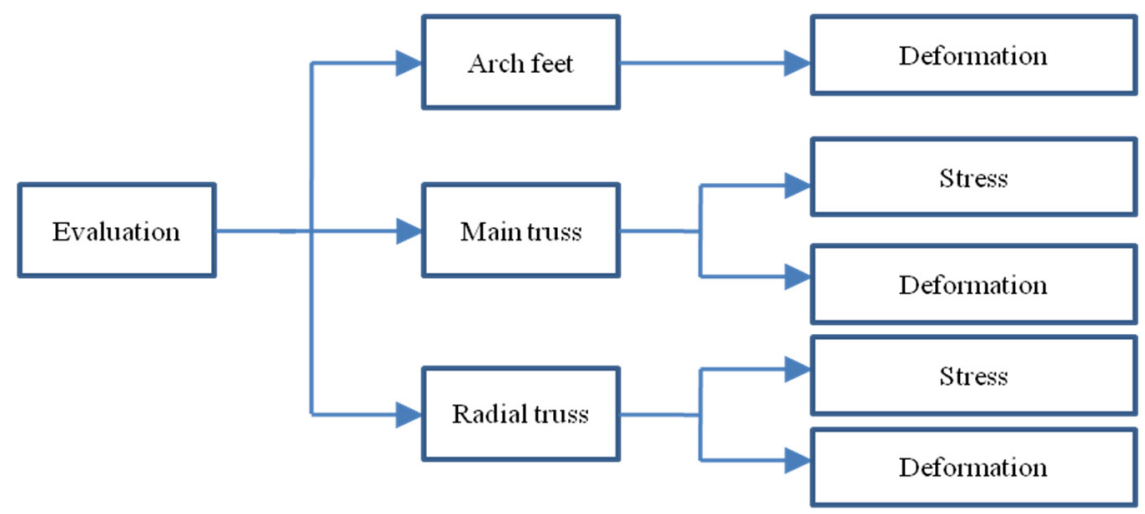

Figure 11. Three types of monitored indicators

The levels and deductions of the underlying indicators are shown in the table 4. Among them, "a" indicates that the monitoring data is less than the theoretical calculation value, and " $\mathrm{b}$ " indicates that it is greater than one time the theoretical calculation value and less than twice the theoretical calculation value, and "c" indicates that it is greater than twice the theoretical calculation value.

Table4. Deductible value of the indicator

\begin{tabular}{cccc}
\hline \multicolumn{4}{c}{ Stress } \\
\hline classification & $\mathrm{a}$ & $\mathrm{b}$ & $\mathrm{c}$ \\
\hline Tolerance & $<[\sigma]$ & $<2.0[\sigma]$ & $>2.0[\sigma]$ \\
\hline $\begin{array}{c}\text { Deduction } \\
\text { value }\end{array}$ & 0 & 15 & 40 \\
\hline \multicolumn{4}{c}{ Deformation } \\
\hline classification & $\mathrm{a}$ & $\mathrm{b}$ & $\mathrm{c}$ \\
\hline Tolerance & $<\triangle$ & $<2.0 \triangle$ & $>2.0 \triangle$ \\
\hline $\begin{array}{c}\text { Deduction } \\
\text { value }\end{array}$ & 0 & 15 & 40 \\
\hline
\end{tabular}

The calculation result of the fuzzy evaluation is carried out by the analytic hierarchy process divided into three levels of indicators. The weight of the second-level indicators is determined according to the importance of the monitoring components. Among them, the monitoring of the arch foot and the main truss is the most critical determined by the expert measurement method. Therefore, the weights are based on the expert survey method, the values of these two parts are the largest, and the weights of the secondary indicators are $0.45,0.45$ and 0.1 respectively. The corresponding calculation formulas are as $(1) \sim(5)$.

$$
\begin{aligned}
S & =\sum_{i=1}^{3} A_{i} \cdot w_{i} \\
A_{i} & =\sum_{j=1}^{2} B_{j} \cdot w_{i j}=\sum_{j=1}^{2}\left(100-D_{j}\right) \cdot w_{i j}
\end{aligned}
$$

$$
\begin{aligned}
& D_{j}=\sum P_{k} \cdot w_{k} \\
& w_{k}=3.0 \mu^{3}-5.0 \mu^{2}+3.0 \mu \\
& \mu=\frac{P_{k}}{\sum P_{k}}
\end{aligned}
$$

In the above formula, " $\mathrm{S}$ " is the comprehensive score, and "Ai" is the score of the second-level indicator, and "wi" is the second -level weight determined by the expert survey method, and "Bj" is the single score of the thirdlevel indicator, and "wij" is the weight value of the thirdlevel indicator which is the element contained in a single indicator of the second level, and " $\mathrm{Dj}$ " is the deduction

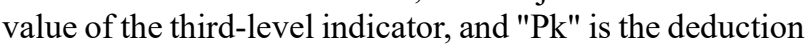
value of the third level indicator, and "wk" is the weight value which is the calculation formula for the weight value of the third level indicator, and $\mu_{\text {is the proportion which }}$ is the ratio of the single deduction system of the third level indicator to the total deduction value.

And the following example is used to illustrate the calculation process of this method, and the data is shown in table 5, and combined with the previous limit deduction conditions, the fuzzy evaluation value of this example can be calculated as 82 points, and the rating is level one.

Table5. Example data

\begin{tabular}{cccccc}
\hline data & w11 & w21 & w22 & w31 & w32 \\
\hline 1 & $\mathrm{~b} 1<[\Delta]$ & $\mathrm{c} 1<[\sigma]$ & $\mathrm{d} 1<[\Delta]$ & $\mathrm{e} 1<[\sigma]$ & $\mathrm{f} 1<[\Delta]$ \\
\hline 2 & $\mathrm{~b} 2<[\Delta]$ & $\mathrm{c} 2<[\sigma]$ & $\mathrm{d} 2<[\Delta]$ & $\mathrm{e} 2<[\sigma]$ & $\mathrm{f} 2<[\Delta]$ \\
\hline 3 & $\mathrm{~b} 3>2.0[\Delta]$ & $\mathrm{c} 3<[\sigma]$ & $\mathrm{d} 3<[\Delta]$ & $\mathrm{e} 3<[\sigma]$ & $\mathrm{f} 3<[\Delta]$ \\
\hline
\end{tabular}

The calculation process has been described through the above examples. The fuzzy evaluation value of the construction monitoring of the west stand structure can be calculated from the data in Table 1 and Table 2. In the process of solving, pay attention to the abnormal data collection or the situation that the data exceeds twice the theoretical value, and the data is substituted into the 
formula (1) -(5), the fuzzy evaluation value of the unloading stage can be calculated as 100 , and the evaluation level is the first level.

\section{Conclusion}

Through the previous discussion in this article, the following conclusions can be drawn.

Through the real-time monitoring of structure construction stage, the results show that the stresses of arch vault and arch foot have a sudden change during the unloading phase, and the range is about $20 \mathrm{MPa} 40 \mathrm{MPa}$, which is far less than the yield strength of the material, and the measured value during the unloading phase agrees well with the theoretical calculation value. The stress state of each measuring point is always in an elastic working state, and the bearing capacity of the entire structure is safe and meets the design requirements.

The horizontal deformation of the arch foot has a sudden change when the roof structure is unloaded, but the deformation of the arch foot slightly decreases and gradually stabilizes, and the deformation of the radial truss measurement points has not changed significantly, and the distance between the two measuring points of the arch foot is pushed outward after the tire frame is removed, but the actual monitoring result is smaller than the theoretical value, indicating that the structural stiffness meets the design requirements.

The analysis of the monitoring results shows that the monitoring method of the project is reasonable, the measured values are in good agreement with the theoretical calculation results, and the monitoring results accurately reflect the actual stress state, which is of great significance for ensuring the safety of the structure. The construction simulation analysis, construction monitoring process and monitoring results in this article can provide references for similar structures.

A fuzzy evaluation method is proposed by dividing the structure monitoring into several parts according to the expert survey method, and using the layered weighting method to score the entire monitoring structure, the scoring result can better reflect the structure construction Monitoring the status. This method is more practical and simple, which can better distinguish the total evaluation value of each construction monitoring stage, and provide reference for related research.

\section{Acknowledgements}

The paper supported by the Special Funds of Guangdong Science and Technology Department Project(2016A040403125) And

Research on Teaching Method Reform of Bridge Inspection Based on Practical Application" (Project Number: GDJX2017018)

\section{References}

1. X.H.Liu, M.Y.Wang, Y. Zhang. "Installation technique and stability checking calculation of top arch tube truss structure in Shenzhen kingkey financial center".Steel Construction. Vol.33. no.1. pp. 92-96,52. 2018.

2. H.F.Chen, X.W.Liui, X.J.Wu, W.D.Xia, S.P.Zhang. "Construction Technology of Partial Continuous Cumulative Unloading of Large-span Space Pipe Truss". Construction Technology, Vol. 46. No.15. pp.34-37,53. 2017.

3. X.D.Shao, G.He, X.J.Shen, P. Zhu,Y. B. Chen. "Conceptual design of $1000 \mathrm{~m}$ scale steel-UHPFRC composite truss arch bridge.Engineering Structures". Vol.226, No.1.PP.1-12.2021.

4. S. Afshan, M. Theofanous, J. Wang, M. Gkantou, L. Gardnere."Testing, numerical simulation and design of prestressed high strength steel arched trusses".Engineering Structures.

Vol.183,No.15.pp510-522.2019.

5. W. Wang, M.F. Wang, S.H. XU, Z.Y. Wang, K.Zhang. "Research on second of large span arch pipe truss structure node during unloading process". Architecture Technology. Vol.47.No.4. pp.368-370. 2016

6. H.P.Xie, Z.C.Jin, Z.L.Luo. "Consturction of Largespan Inclined Arch Pipe Truss Installation. Construction Technology". Vol.46. No.7.pp.3335.2017

7. Y. Mesda. "Analytical Study of the Cable-Truss Systems on the Glass Certain Walls with Vertical Uses". Engineering. Vol.5.No.10. pp.819-826.2013.

8. B.Wu, L.L. Zhang, Y. Yang, L.J. Liu, Z.J. Ni. Claudio Mazzotti. "Refined Time-Domain Buffeting Analysis of a Long-Span Suspension Bridge in Mountainous Urban Terrain.Advances in Civil Engineering". Advances in Civil Engineering. Vol. 2020.No.1.pp.122. 2020.

9. K.L. Chen, G.Q. Yuan, L.K. Wang, W.Z. Zhang, X.K. Wang. "Research on Construction Monitoring of Large-Span Steel Pipe Truss Structure". Open Journal of Civil Engineering. Vol. 9. No. 4. PP. 255-267.2019.

10. X.L.Wang, Z.H.Rong, B.X.Yang, C.D.Luo, Y.Zhou, X.Y.Wu. "Whole Process Simulation Analysis and health monitoring of spatial Pipe Truss Structure Gymnasinm". Journal of Architecture and Civil engineering. Vol. 34.No.2. pp. 18-25. 2017.

11. Ministry of Construction of the People's Republic of China.Technical code of maintenance for city bridge(CJJ99-2003). 2003 